\title{
Para uma Renovação da Crítica do Direito a Partir dos Estudos Críticos do Discurso*
}

\author{
For a Renovation of the Critical of Law from \\ Critical Discourse Studies
}

\author{
Ricardo de Macedo Menna Barreto ${ }^{1}$
}

Resumo: O presente artigo tem por escopo realizar uma proposta de compreensão Crítica do Direito a partir dos Estudos Críticos do Discurso do linguista holandês Teun A. van Dijk. Nesse sentido, revisitam-se as relações entre Direito e Linguagem, visto que os estudos críticos de van Dijk permitem também uma atualização deste movimento em sua interseção com a Crítica do Direito. Quanto à metodologia, estabeleceu-se uma discussão crítica a partir do conhecimento partilhado pelo diálogo interdisciplinar, enquanto a técnica/método de pesquisa utilizado para a presente abordagem foi a bibliográfica. Entende-se que a articulação dos ECD de van Dijk com a Crítica do Direito pode orientar nos lineamentos iniciais de uma "Crítica Linguística do Direito" bastante atual e condizente com os caracteres da sociedade contemporânea.

Palavras-chave: Crítica do Direito. Direito e Linguagem. Estudos Críticos do Discurso.

\begin{abstract}
The purpose of this paper is to propose a comprehension of the Critique of Law from the Critical Discourse Studies of Dutch linguist Teun A. van Dijk. In this sense, the relations between Law and Language are revisited, since van Dijk's critical studies also allow an update of this movement in its intersection with the Critique of Law. As for the methodology, a critical discussion was established from the knowledge shared by the interdisciplinary dialogue, while the research technique/method used for the present approach was bibliographic. It is understood that the articulation of van Dijk's ECD with the Criticism of Law can guide the initial guidelines of a current "Linguistic Critique of Law" that is consistent with the characteristics of contemporary society.

Keywords: Critique of Law. Law and Language. Critical Discourse Studies.
\end{abstract}

\footnotetext{
* O presente artigo será igualmente publicado, em versão impressa, na Revista Scientia Iuridica, Tomo LXIX, n. 352, 2020, Braga, Portugal (no prelo). O autor agradece às Editoras-Chefes de ambas revistas pela autorização para publicação simultânea nos dois países.

${ }^{1}$ Doutor em Ciências Jurídicas pela Universidade do Minho, Portugal. Mestre em Direito Público pela UNISINOS, RS, Brasil. Graduado em Direito pela UNISINOS, RS, Brasil. Professor Convidado nos Programas de Mestrado em Direito e na Licenciatura em Direito da Escola de Direito da Universidade do Minho, Portugal.
} 


\section{Introdução}

O presente artigo propõe-se a revisitar as relações entre Direito e Linguagem a partir da Crítica do Direito, visando, especificamente, apresentar as contribuições dos Estudos Críticos do Discurso (ECD) de Teun A. van Dijk para uma renovação da Crítica do Direito. Nesse sentido, procuraremos demonstrar como os ECD e a Crítica do Direito podem ser articulados tanto na combinação de aspectos teórico-metodológicos, quanto de aspectos empírico-sociais para uma atualização do pensamento crítico do Direito. Entendemos que, com a devida recepção dos ECD no campo jurídico, pode-se obter um instrumental teórico rico e muito apto a estudar criticamente certas propriedades linguísticas do discurso jurídico, permitindo que se perceba, a partir daí, "empiricamente", a existência de práticas sociais ilegítimas e por vezes ilegais, como, por exemplo, o abuso de poder discursivo por parte dos juízes ${ }^{2}$.

Com efeito, os ECD de van Dijk podem possibilitar uma atualização da Crítica do Direito na medida em que identificamos uma equivalência funcional metalinguística entre os ECD e a (teoria) Crítica do Direito. Isso se deve, sobretudo, ao fato de ambas as perspectivas (embora em campos distintos, é certo) realizarem uma crítica social, fruto de certa insatisfação com o inscrito e o instituído na sociedade. Logo, a cumulação dos subsídios teórico-metodológicos dos ECD, com os estímulos do pensamento jurídico crítico, pode auxiliar para uma compreensão diferenciada do discurso jurídico na contemporaneidade.

Quanto à metodologia, procuramos estabelecer uma compreensão crítica de teorias linguísticas e jurídicas a partir do conhecimento partilhado pelo diálogo interdisciplinar. Seguindo as valiosas sugestões metodológico-

\footnotetext{
2 Porém, por questões de espaço e delimitação, buscaremos, neste artigo, apenas apresentar esta proposta de atualização da Crítica do Direito pelos Estudos Críticos do Discurso, condicionando a um momento futuro a publicação de análises de casos judiciais à luz deste instrumental crítico-linguístico.
} 
científicas de Pedro Demo (2012), assentamos esta pesquisa no rigor formal científico, no questionamento sistemático crítico e criativo e na intervenção inovadora. Ademais, não propomos, com este estudo, a formação de alguma espécie de bloco teórico, ou mesmo de "seita epistemológica" (hoje infelizmente tão presentes em algumas matrizes do pensamento crítico do Direito), mas de um consenso cientificamente argumentado (DEMO, 2012) ${ }^{3}$. Já a técnica/método de pesquisa utilizado para a presente abordagem foi a bibliográfica.

O presente artigo divide-se em três grandes partes. A primeira (1), intitulada "Crítica do Direito e Dogmática Jurídica", aborda os caracteres gerais da Crítica do Direito, observando tal movimento, em sentido amplo, como uma crítica ao reducionismo da dogmática jurídica. Aborda-se, assim, um específico movimento para análise (Critique du Droit), por ter este influenciado alguns dos juristas latino-americanos responsáveis pelas mais importantes abordagens críticas do fenômeno jurídico a partir do estudo das relações entre Direito e Linguagem. Por conseguinte (2), em "Direito e Linguagem e Análise Crítica do Discurso", apresentam-se os caracteres gerais do movimento teórico comumente conhecido como "Direito e Linguagem", com ênfase nos estudos realizados em solo brasileiro. Em seguida - a título de introdução à seção seguinte -, apresenta-se o movimento conhecido como Análise Crítica do Discurso (ACD), cujas bases epistemológicas forneceram os subsídios para o desenvolvimento do referencial escolhido para esta pesquisa (Teun A. van Dijk). Por fim, em (3) "Estudos Críticos do Discurso: Elementos Para uma Renovação da Crítica do Direito", aborda-se a proposta teórico-linguística de van Dijk, os Estudos Críticos do Discurso (ECD). Apresentaremos seus caracteres basilares para

\footnotetext{
3 Atualmente, no âmbito da Crítica do Direito, tem-se um certo sectarismo, partidarismo, azedume e mau humor, elementos combinados na tentativa de (a qualquer preço) salvaguardar um pensamento "crítico" oficial. Quando trabalhados deste modo, os questionamentos críticos se dirigem mais à destruição do que à crítica em si. Para Demo, é preferível optarmos pela emulação dialética e pela contribuição criativa na discussão crítica de ideias e teorias.
} 
articular, posteriormente, estes estudos com a Crítica do Direito - visto ambos os movimentos (ECD e Crítica do Direito) realizarem uma crítica social resultante da inconformidade com o inscrito e o instituído na sociedade contemporânea e com as relações de poder e dominação social.

Reconhecemos que outras matrizes linguísticas contemporâneas podem, eventualmente, permitir a articulação de um ponto de renovação da Crítica do Direito. Todavia, entendemos que será notadamente a partir dos ECD que - como dirá Bakhtin (2017, p. 79) - “cada sentido terá sua festa de renovação. Questão do grande tempo".

\section{Crítica do Direito e Dogmática Jurídica}

A Teoria Crítica do Direito, ou Crítica do Direito, é marcada por distintos movimentos teóricos, todos com uma preocupação comum, qual seja, a de estabelecer certa compreensão sobre "o modo como o direito cria sistemas de classificação e de hierarquização, normas e imagens, que condicionam ou até instituem, relações de poder na sociedade", conforme bem acentua António Manuel Hespanha (1997, p. 224).

Um dos principais papéis da teoria crítica do direito é, decerto, a denúncia da função ideológica que encobre a própria fundamentação do jurídico. É o que entende, por exemplo, Carlos Maria Cárcova, quando explica que o papel da teoria crítica do direito é o de impugnar o reducionismo normativista que supõe a existência de um "mero jogo de disposição e organização metodológica" do Direito. Com isso, tal crítica postula dar conta das condições históricas do surgimento do discurso da lei, bem como de sua própria produção, circulação e apropriação, desvelando os interesses que se encontram em sua base. Trata-se, com efeito, de uma teoria que concebe o Direito como uma instância específica da totalidade social, dando-se especial atenção à análise de seus elementos estruturais e partindo de uma matriz explicativa multi e transdisciplinar. Isso se opera, 
segundo Cárcova (1991, pp. 07-08), como uma espécie de "discurso de intersecção", para o qual concorrem múltiplos saberes, como, por exemplo, a linguística, a sociologia, a economia política, a antropologia, etc.

Pode-se dizer que a nível mundial os mais conhecidos movimentos teórico-críticos do Direito desenvolveram-se, sobretudo, em França (Critique du Droit), nos Estados Unidos da América (Critical Legal Studies) e na Alemanha (Rechtskritik) (HESPANHA, 1997, p. 225), não obstante o facto de as suas influências terem se difundido por diferentes países e terem adquirido diferentes matizes epistemológicos.

Não obstante, independentemente do matiz teórico, em sentido amplo a Crítica do Direito pode ser compreendida enquanto uma crítica à (ou ao reducionismo da) dogmática jurídica - premissa da qual partilham, de algum modo (e, decerto, de maneiras diferentes) todos os três movimentos críticos mencionados. Conceitualmente, a dogmática jurídica, segundo Niklas Luhmann (1983, pp. 27-34), tem como característica mais marcante a chamada proibição de negação, ou seja, a não-negabilidade dos pontos de partida das cadeias argumentativas. Soma-se a isso a pressuposição de certo nível de organização do sistema jurídico, possibilitando a tomada de decisões vinculantes acerca das problemáticas jurídicas. Em outras palavras, a dogmática jurídica oferece, segundo Luhmann, uma entre várias soluções que são equivalentes funcionalmente para o problema da aplicação do direito, controlando, assim, uma grande quantidade de decisões possíveis.

Porém, para além da concepção luhmanniana, podemos afirmar que a dogmática jurídica "é qualquer coisa, menos algo claro", como adverte Robert Alexy (2007, pp. 240-241), pois não há, segundo este autor, uma "teoria da dogmática jurídica" compartilhada de modo unânime. Geralmente, diz Alexy, por dogmática jurídica entende-se a Ciência do Direito em sentido próprio e estrito, sendo ela uma mescla de três atividades: 1) descrever o direito vigente; 2) realizar uma análise sistemática e conceitual e 3) elaborar propostas para a solução de casos jurídicos complexos. Ante a complexidade 
do desenvolvimento destas atividades, Alexy afirma que a dogmática jurídica pode ser considerada uma “disciplina pluridimensional". Em sua concepção discursiva da dogmática jurídica, Alexy traça uma linha de pensamento que relaciona a dogmática jurídica com os ditos "argumentos dogmáticos". Como tais argumentos devem estar apoiados na dogmática jurídica, é conveniente entendê-la não como um conjunto de atividades, mas sim de enunciados. Nesta óptica, Alexy define a dogmática do Direito (ou jurídica) como uma

[...] série de enunciados que se referem às normas estabelecidas e à aplicação do Direito, porém não podem se identificar com sua descrição, estando entre si em uma relação de coerência mútua, se formando e discutindo no marco de uma ciência jurídica que funciona institucionalmente, tendo conteúdo normativo" (ALEXY, 2007, p. 246). ${ }^{4}$

A partir daí, a crítica à dogmática jurídica pode ser compreendida como uma crítica às insuficiências do direito positivo, o qual tem seus próprios critérios de racionalidade e neutralidade - reproduzidos, hoje, larga e cegamente, pelo ensino jurídico e pela práxis jurídica, de modo inteiramente acrítico. Abre-se, assim, um amplo espaço a críticas à luz de diferentes vertentes.

Entre os três grandes movimentos críticos anteriormente mencionados, escolheremos um em particular (Critique du Droit) para abordar, pelo fato deste ter influenciado importantes juristas brasileiros, os quais passaram a desenvolver abordagens críticas do fenômeno jurídico nomeadamente a partir das relações entre Direito e Linguagem, relações estas que interessam a este estudo.

Entre as mais vultosas obras jurídico-críticas publicadas na França destaque-se "Une Introduction Critique au Droit" (Uma Introdução Crítica ao Direito), do jurista francês Michel Miaille. Apontando para suas bases

\footnotetext{
${ }^{4}$ Tradução (adaptação) livre de: "(1) una serie de enunciados que (2) se refieren a las normas establecidas y a la aplicación del Derecho, pero no pueden identificarse con su descripción, (3) están entre si en una relación de coherencia mutua, (4) se forman y discuten en el marco de una ciencia jurídica que funciona institucionalmente, y (5) tienen contenido normativo".
} 
teóricas, Miaille defenderá a necessidade de um regresso aos clássicos marxistas, afirmando categoricamente que, para o sucesso de tal investida, "o texto mais claro e mais interessante continua a ser o de E. B. Pašukanis (...)" (MIAILLE, 1979, p. 10). Contudo, Miaille, ao propor sua "introdução crítica”, avança significativamente em relação ao legado teórico de Pašukanis (1977).

Miaille entende que para se "introduzir" o Direito, deve-se introduzilo "cientificamente", ou seja, como uma ciência jurídica. Desta maneira, este jurista francês se distancia de todo um manancial de disciplinas e manuais que seguiam, até então, uma espécie de "melodia única", qual seja, a da "filosofia idealista dos países ocidentais, industrializados". Miaille sustentará então que uma introdução crítica deve ser diferenciada de uma introdução com críticas, pois a ideia de "crítica" deve ser tomada em seu sentido mais profundo, qual seja, possibilitando que apareça o invisível. Não se trata de uma concepção mística ou esotérica, pois a crítica envolve, para Miaille, um verdadeiro exercício de abstração intelectual, evocando coisas, ou realidades, diante de sua ausência (MIAILLE, 1979, pp. 16-17). O pensamento crítico não se resume, porém, ao pensamento abstrato; por isso, sustenta Miaille, é preciso acrescentar-lhe a dialética. "Que quer isto dizer? O pensamento dialéctico parte da experiência de que o mundo é complexo: o real não mantém as condições de sua existência senão numa luta, quer ela seja consciente ou inconsciente” (MIAILLE, 1979, pp. 17-18).

E é esta complexidade própria da conjuntura social que normalmente coloca "em cheque" os juristas mais dogmáticos. Isso porque, ante a crescente flutuação das estruturas sociais, surgem, invariavelmente, novos desafios e demandas jurídicas que levam o pensamento jurídico dogmático a ver-se "em conflito" na busca por respostas (prontas) mais adequadas à sempre mutável e contingente realidade social. Nesta ordem de ideias, Miaille (1979, p. 19) afirmará que 
a teoria crítica permite não só descobrir os diferentes aspetos escondidos de uma realidade em movimento, mas sobretudo abre, então, as portas de uma nova dimensão: a da 'emancipação', segundo o termo de G. Raulet. Reflectindo sobre as condições e os efeitos da sua existência na vida social, a teoria reencontra a sua ligação com a prática, quer dizer, com o mundo social existente.

Importante observar que esta corrente, muito bem representada por Miaille, é composta também por outros importantes juristas franceses. Conforme Fragale Filho e Rezende Alvim (2007, p. 146), este movimento surge, efetivamente, a partir da coleção de obras Critique du droit, "dirigida por Robert Charvin, Philippe Dujardin, Jean-Jacques Gleizal, Antoine Jeammaud, Michel Jeantin e Michel Miaille, e que publicou, no final dos anos 1970 e início dos anos 1980, pelo menos cinco diferentes volumes (...)”.

O estudo de Fragale Filho e Rezende Alvim (2007, p. 141) traça um interessante panorama da influência do movimento Critique du droit no Brasil. Tomando como ponto de partida não apenas a coleção Critique $d u$ droit, mas também a revista Procès - Cahiers d'analyse politique et juridique, periódico científico veiculado pelo Centre d'épistémologie juridique et politique da Universidade de Lyon II desde 1978, os autores explicam os reflexos deste movimento em solo brasileiro. A recepção da Critique du droit pela comunidade acadêmica brasileira foi tão considerável que um dos números da revista Procès, no ano de 1982, foi inteiramente dedicado às “Abordagens Críticas do Direito na América Latina”.

As reflexões de Michel Miaille apontam, pois, para uma postura reflexiva, na qual os cientistas do Direito devem pôr-se a pensar a natureza dos próprios conceitos que manejam na Ciência do Direito. Não se trata, porém, de uma ciência independente, ou mesmo "pura" (como pretendia Kelsen [2000]), pois este tipo de análise crítica "desbloqueia o estudo do direito do seu isolamento, projecta-o no mundo real onde ele encontra o seu lugar e a sua razão de ser, e, ligando-o a todos os outros fenómenos da sociedade, torna-o solidário da mesma história social” (MIAILLE, 1979, p. 19). 
Como referimos, Miaille e seus colegas franceses do movimento Critique $d u$ droit exerceram grande influência na crítica do Direito no Brasil. Nesse sentido, o jurista argentino Luis Alberto Warat, idealizador das Jornadas Latino-americanas de Metodologia do Ensino do Direito, então sediado e lecionando no Brasil, chegou, em certa oportunidade, a recepcionar Michel Miaille, Antoine Jeammaud, entre outros nomes da crítica do Direito francesa ${ }^{5}$. Tal aproximação possibilitou a criação e difusão de uma corrente crítica de influência francesa assente, sobretudo, no sul do Brasil.

Para fins de contextualização, vale observar que, na década de 1970, Luis Alberto Warat cria, em Buenos Aires, a ALMED (Associação LatinoAmericana de Metodologia do Ensino do Direito), a partir da qual organizaria diversas jornadas e publicações na área de metodologia e ensino do direito, tanto na Argentina como no Brasil. Tal aproximação com o Brasil fez com que Warat se mudasse de Buenos Aires para o Brasil ainda na década de 1970 - inicialmente para a Universidade Federal de Santa Maria (UFSM), em Santa Maria, Rio Grande do Sul e, posteriormente, nos anos 1990, para a Universidade Federal de Santa Catarina (UFSC), em Florianópolis, Santa Catarina, onde ajuda a fundar o Programa de PósGraduação em Direito da UFSC junto a importantes nomes da crítica jurídica, como Leonel Severo Rocha. Mais tardiamente, depois dos anos 2000, na Universidade de Brasília (UnB), em Brasília (DF), Warat também orientaria José Geraldo de Souza Jr., um dos precursores do movimento jurídico-crítico "Direito Achado na Rua" ${ }^{6}$.

Deste modo, forjava-se uma plêiade de juristas críticos inicialmente influenciados pela corrente crítica francesa e situados, sobretudo, na região sul do Brasil. Nesse sentido, percebe-se que Luis Alberto Warat e Leonel Severo Rocha exerceram um papel decisivo, trazendo esta dimensão crítica

\footnotetext{
${ }^{5}$ Para um panorama geral da influência francesa em juristas brasileiros, ver FRAGALE FILHO, R. e REZENDE ALVIM, J. L. (2007).

${ }^{6}$ Autor que, por sua vez, sofreu forte influência também do pensamento crítico de LYRA FILHO (1980).
} 
do estudo do Direito tanto para a UFSC como, posteriormente (fins dos anos 1990), para a Universidade do Vale do Rio dos Sinos (UNISINOS), em São Leopoldo (RS), instituição na qual este movimento crítico se reproduz até os dias atuais - contudo, atualmente, relativamente distante de suas raízes críticas francesas, dando maior ênfase para filósofos e juristas alemães, notadamente no campo da Hermenêutica Jurídica (Gadamer) e da Sociologia Jurídico-Sistêmica (Luhmann).

Feita esta breve abordagem, não seria demais observar que hoje os principais movimentos crítico-jurídicos compartilham de alguns pontos dos quais também compartilhamos: i) certo inconformismo com o paradigma positivista-dogmático do direito; ii) a necessidade de se repensar criticamente o jurídico inscrito e instituído no social; e iii) a necessidade de se buscarem respostas jurídicas mais condizentes com a complexidade do contexto social contemporâneo. Não obstante, é a partir das relações entre Direito e Linguagem (2) que buscaremos esboçar uma proposta de renovação da Crítica do Direito, conforme se verá a seguir.

\section{Direito e Linguagem e Análise Crítica do Discurso}

Estudos sobre a linguagem importam para o Direito pelo fato da linguagem ser inarredável de nossas emoções e valores, bem como do próprio pensar e agir humano. A linguagem, nesta perspectiva, pode ser considerada o ponto limítrofe, a fronteira de nossa própria humanidade. Através dela, desenvolvemos nossas experiências e vivências. Com a linguagem também construímos o mundo social e o jurídico. Nesse sentido, Joana Aguiar e Silva (2011, p. 33) afirma que "o mundo do Direito é um mundo que se move, nas suas mais diversificadas facetas, ao longo dos trilhos sulcados pela palavra, pelo texto, pelo discurso escrito ou oral”.

Note-se, contudo, que, do ponto de vista linguístico e social, uma das principais características do discurso jurídico é o seu "hermetismo", isto é, 
seu fechamento, o que o torna praticamente inacessível aos "não-iniciados". Por isso, para Pierre Bourdieu (2007, p. 232), são os profissionais do Direito que produzem uma espécie de "necessidade" de seus próprios serviços, ao transformarem - em problemas jurídicos - certos problemas que se exprimem na linguagem vulgar, ou seja, traduzem-nos para a linguagem do direito.

No âmbito latino-americano dos estudos jurídicos sobre a linguagem, sabe-se que um rol de notáveis teóricos do Direito foram estimulados (especialmente nas últimas três décadas do século passado) pela semiótica de Peirce (2003), pela semiologia de Saussure (2012), pela filosofia de Carnap (1969), entre outros contributos de inúmeros pensadores dirigidos à linguística ou à filosofia (ou mesmo à filosofia da linguagem).

Especificamente em solo brasileiro, tais discussões ganharam especial espaço a partir da década de 1970, sobretudo no âmbito da Crítica do Direito de Luis Alberto Warat. Na esteira do pensamento waratiano, Leonel Severo Rocha (2005, p. 26) explica como análises relativamente sistematizadas sobre os signos jurídicos foram provocadas, principalmente, por três influências: a) a Lógica Jurídica; b) a Nova Retórica; e c) a Escola Analítica de Buenos Aires. E a semiótica jurídica, propriamente dita, passou a ganhar espaço no Brasil ainda nos anos 1970 a partir da obra de Warat (1995).

Note-se como, estimulado por diferentes autores, Warat procurou estudar as funções sociais, os efeitos políticos e ideológicos dos diferentes discursos jurídicos [especialmente do discurso docente e do discurso da dogmática jurídica] (WARAT, 1980, pp. 146-152), reconhecendo, à luz de sua semiologia do poder (WARAT, 1981), que

as significações não deixam de ser um instrumento de poder. Aceitando-se que o direito é uma técnica de controle social não podemos deixar de reconhecer que seu poder só pode manter-se estabelecendo-se certos hábitos de significação (WARAT, 1987, pp. 58-59). 
Por outro lado, mas em perspectiva teórica um pouco diversa, Tércio Sampaio Ferraz Jr., estimulado por Theodor Viehweg (1986), realizou uma análise da pragmática da comunicação jurídico normativa. A proposta de Ferraz Jr. foi tratar o direito do ponto de vista normativo, encarando a norma em sua dimensão linguístico-pragmática. Sua proposta não foi propriamente estudar a linguagem do direito ou sua manifestação normativa, mas investigar como o próprio Direito necessita, para sua existência, da linguagem (FERRAZ JR., 2005, pp. 05-07).

Há não muito tempo, Eduardo C. B. Bittar (2006) também partiu para uma análise semiótica do direito, porém, ainda transitando em geral dentro do inventário teórico já abordado por outros autores. Assim, detectou-se que, desde tais contribuições, manteve-se relativamente estático o quadro teórico das pesquisas sobre Direito e Linguagem em solo brasileiro.

Vale observar como, por outro lado, também nos Estados Unidos da América, nas décadas de 1970 e 1980 em especial, as descobertas de uma variada gama de pesquisadores de diferentes origens passaram a convergir para uma área de pesquisa designada "Law and Language" (CONLEY e O'BARR, 1998, p. 09). Esta área foi fortemente influenciada por dois campos pré-existentes, conforme explicam John Conley e William O’Barr (1998, p. 09): sociolinguística (sociolinguistics) e direito e sociedade (law and society), movimentos que se destacaram por terem estabelecido um ponto de partida epistemológico para que os estudos de "direito e linguagem" se tornassem possíveis em solo americano.

Embora todos estes diferentes estudos tenham se dirigido, com grande sucesso, não apenas a uma análise linguística do fenômeno jurídico, mas, igualmente, a uma crítica da dogmática jurídica, até onde se pôde verificar eles não se envolveram, de modo mais aprofundado, com as complexas interrelações do discurso jurídico com outros discursos (como o midiático, o político, etc.) e, neste contexto, especificamente, com as questões ideológicas e de uso ilegítimo de poder que os envolvem. Por outro lado, tais estudos 
parecem também não ter se dirigido às perspectivas crítico-linguísticas mais recentes, como aquela que pretendemos apresentar neste texto.

Contemporaneamente, entendemos serem os Estudos Críticos do Discurso (ECD) o referencial linguístico que oferece um inovador ponto de intersecção com a Crítica do Direito, fazendo uso de uma diversificada quantidade de métodos de análise e concentrando-se, de forma específica, "nas complexas relações entre a estrutura social e a estrutura discursiva, bem como no modo como as estruturas discursivas podem variar ou ser influenciadas pela estrutura social” (DIJK, 2012, p. 13). Note-se que, de acordo com van Dijk, estudos envolvendo a análise do discurso se centraram, durante muito tempo, nas propriedades linguísticas da textualidade, como a coerência semântica e sua expressão gramatical. Assim, apenas mais recentemente, pensou-se o discurso à luz de problemas sociais mais amplos, em instituições e organizações (DIJK, 1997, p. 15).

Decerto, no campo jurídico não foi muito diferente: análises das estruturas discursivas voltaram-se, sobretudo, à semiótica do discurso, descuidando-se da necessária integração da análise das estruturas discursivas com teorias sociais e culturais mais abrangentes. Tais perspectivas não aprofundaram, consequentemente, questões socialmente relevantes, como o contexto do discurso, as ideologias e as relações de poder existentes em grupos e instituições, bem como o modo como estas se perpetuam.

Antes, porém, de partirmos para uma compreensão dos aspectos basilares dos Estudos Críticos do Discurso - e de como estes estudos podem contribuir para a Crítica do Direito -, precisamos situá-los no seio de um espaço teórico mais amplo, do qual tais estudos críticos derivam: a Análise Crítica do Discurso (ACD).

A Análise Crítica do Discurso trata-se de um movimento teóricolinguístico composto por um grupo de seletos linguistas, cujas preocupações 


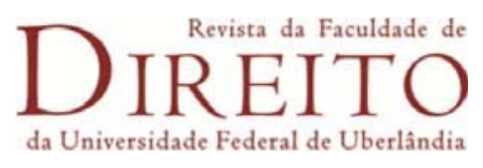

sociais são bastante heterogêneas. Sobre o aparecimento deste importante movimento teórico, Ruth Wodak (2002, p. 04) lembra que a

ACD como uma rede de estudiosos surgiu no início dos anos 1990, após um pequeno simpósio em Amsterdã, em janeiro de 1991. Por acaso e através do apoio da Universidade de Amsterdã, Teun van Dijk, Norman Fairclough, Gunther Kress, Theo van Leeuwen e Ruth Wodak passaram dois dias juntos e tiveram a maravilhosa oportunidade de discutir teorias e métodos de análise do discurso e especificamente $\mathrm{ACD}^{7}$.

Posteriormente este distinto grupo de linguistas expandiu-se, propiciando o surgimento de novas pesquisas na área nas décadas seguintes, cada qual se ocupando com objetos específicos (a mídia, o racismo, etc.), mas carregando sempre um interesse em comum - que é, a saber, conforme van Dijk (1993, p. 249), o estudo das relações entre discurso, poder e dominação. Ruth Wodak (2002, p. 03) não discorda do entendimento de van Dijk, mas o complementa, afirmando que "três conceitos figuram como indispensáveis em todas as Análises Críticas do Discurso: o conceito de poder, o conceito de história e o conceito de ideologia" 8.

Há, pois, um forte entrelaçamento entre estes conceitos. Reconhece-se que questões como dominação e poder perpassam distintos problemas sociais que envolvem, de diferentes formas, o Direito. Como consequência destas questões todas, um dos maiores problemas levantados atualmente pelos analistas críticos do discurso é o da desigualdade social. Segundo van Dijk (1997, pp. 22-23), a ACD visa refletir criticamente acerca da desigualdade social "baseada em gênero, etnia, classe, origem, religião, linguagem, orientação sexual e outros critérios que definem diferenças entre pessoas" 9 .

\footnotetext{
7 Tradução livre de: "CDA as a network of scholars emerged in the early 1990s, following a small symposium in Amsterdam, in January 1991. By chance and through the support of the University of Amsterdam, Teun van Dijk, Norman Fairclough, Gunther Kress, Theo van Leeuwen and Ruth Wodak spent two days together, and had the wonderful opportunity to discuss theories and methods of discourse analysis and specifically CDA".

8 Tradução livre de: "Three concepts figure indispensably in all CDA: the concept of power, the concept of history, and the concept of ideology".

9 Tradução livre de: "(...) based on gender, ethniticy, class, origin, religion, language, sexual orientation and other criteria that define differences between people". No mesmo sentido Wodak (2002, p. 02) afirma que "a ACD tem por objetivo investigar criticamente a
} 
Diretamente relacionada com o problema da desigualdade social, encontra-se, pois, a questão do poder. Poder, na perspectiva da ACD, referese, basicamente, às diferenças na estrutura social (WODAK, 2002, p. 11). Nesse sentido, como sublinha van Dijk (2012, p. 21), o poder "não deve ser definido como o poder de uma pessoa, mas antes como o poder de uma posição social, sendo organizado como parte constituinte do poder de uma organização”.

No entanto, o foco central da ACD nesta dimensão do social, "não retira a atenção a outros aspetos do discurso, nomeadamente as componentes psicológicas e cognitivas e de processamento do discurso" (PEDRO, 1997, p. 20). Assim, o espaço em que operam os analistas críticos do discurso compõe-se, como se percebe, de uma verdadeira plêiade de influências disciplinares e teóricas, formando, como sugere van Dijk, um "complexo e multidisciplinar campo de estudos" (DIJK, 1993, p. 249). Linguística, Sociologia e Psicologia se entrelaçam neste relativamente novo movimento científico que é a Análise Crítica do Discurso, permitindo análises bastante elaboradas dos problemas sociais - daí sustentarmos a importância de um referencial teórico deste matiz para o Direito.

Por outro lado, há certo consenso entre os analistas críticos do discurso no sentido de que outra característica própria da Análise Crítica do Discurso, em suas mais distintas ramificações, é o fato de voltar-se o olhar à linguagem dos mass media, dos objetos da cultura popular, dos contextos burocráticos, bem como da consequente burocratização e tecnização da linguagem. Além disso, a ACD ocupa-se com os discursos jurídico, científico e econômico (DIJK, 1993, p. 249), sendo que, para tanto, fornece um modelo conceitual bastante abrangente, que possibilita que se explicitem formas como as do abuso de poder, da desigualdade e da dominação, que passam a

desigualdade social à medida que ela é expressa, sinalizada, constituída, legitimada e assim por diante pelo uso da linguagem (ou no discurso)". Tradução livre de: "CDA aims to investigate critically social inequality as it is expressed, signaled, constituted, legitimized and so on by language use (or in discourse)". 
ser reproduzidas por determinados discursos marcados pela ideologia (DIJK, 1997, p. 106).

Em verdade, a ideologia assume um caráter central na $\mathrm{ACD}$, pois surge "como um instrumento permanente dos poderes e como o ponto simbólico onde os poderes são incessantemente legitimados ou contestados, reforçados ou enfraquecidos” (ANSART. 1978, p. 11). Há, nesse aspecto, uma forte relação entre conflitos e produção ideológica, segundo adverte Pierre Ansart, de modo que a articulação existente entre a produção da linguagem política e o desenvolvimento dos conflitos levou ao isolamento da linguagem de suas condições sociais de produção (ANSART, 1978, pp. 14-15). Sobre as relações entre ideologia e linguagem, Vivane Resende e Viviane Ramalho (2016, p. 14), duas pesquisadoras da ACD, afirmam que foi Mikhail Bakhtin "o fundador da primeira teoria semiótica de ideologia, da noção de 'dialogismo' na linguagem e precursor da crítica ao objetivismo abstrato de Saussure".

A obra de Bakhtin à qual as autoras se referem é "Marxismo $e$ Filosofia da Linguagem", assinada por Volochínov ${ }^{10}$, mas posteriormente atribuída a Bakhtin. Trata-se de uma filosofia da linguagem de fundamento marxista, na qual Bakhtin (2009, p. 31) sustenta que as bases de uma teoria marxista da criação ideológica encontram-se intimamente ligadas aos problemas da filosofia da linguagem, de modo que "tudo o que é ideológico possui um significado e remete a algo situado fora de si mesmo. Em outros termos, tudo que é ideológico é um signo. Sem signos não existe ideologia”.

Ora, afastando-se dos psicologicismos que sustentam as diversas concepções de ideologia, Bakhtin irá sustentar que a realidade dos fenômenos ideológicos é a própria realidade objetiva dos signos sociais, cujas leis são as leis da comunicação semiótica determinadas pelas leis sociais e

10 V. N. Volochínov foi professor do Conservatório de Música de Vitebsk, amigo e discípulo de Bakhtin. Desaparecido nos anos 1930 por força dos expurgos stalinistas, Volochínov propôs-se assinar "Marxismo e Filosofia da Linguagem" devido ao facto de Bakhtin ter se recusado a fazer as modificações impostas pelo editor à época da publicação (1929). Cfe. YAGUELLO, M. (2009, pp. 11-12). 
econômicas. Assim, o aspecto semiótico da comunicação social pode ser claramente visto na linguagem, sendo a "palavra" "o fenómeno ideológico por excelência”. É a palavra, para Bakhtin (2009, p. 36), que deve estar em primeiro plano no estudo das ideologias, dada a sua representatividade como fenômeno ideológico e a nitidez da sua estrutura semiótica.

Estamos, pois, ante uma proposta epistemológica com vasto campo de aplicação, apta ao tratamento de diversas práticas da vida social, possibilitando o mapeamento de relações entre os recursos linguísticos utilizados por diferentes grupos de atores sociais e aspectos da rede de práticas em que está inserida a interação discursiva (RESENDE e RAMALHO, 2016, pp. 11-12). Nesse sentido, a relevância da Análise Crítica do Discurso encontra-se na própria reunião da análise linguística com a teoria social, marcadamente a partir de um olhar crítico da linguagem como prática social. E, vale observar, as mais diversas formas de análise do discurso tomam o texto como o domínio adequado da teoria e da descrição linguísticas, no entanto, a ACD, de modo diferenciado, visa dar conta tanto da estrutura interna, como da organização global dos textos, com o objetivo de fornecer uma dimensão crítica (social) à análise dos textos (PEDRO, 1997, p. 23).

Finalmente, pode-se levantar o seguinte questionamento: como se procede, "na prática", à análise crítica do discurso? Segundo Teun van Dijk (2002, p. 97), independentemente das dimensões do discurso que a Análise Crítica do Discurso trate, este movimento científico, como forma "específica e prática" de análise discursiva, precisa sempre explicar, pelo menos, algumas das estruturas, estratégias e funções que aparecem no texto, incluindo aí a gramática, a pragmática, bem como as formas interacionais, estilísticas, retóricas, semióticas, narrativas ou similares de organização verbal e paraverbal de eventos comunicativos.

Vistos estes caracteres gerais da Análise Crítica do Discurso, passaremos, no seio deste grande movimento, a observar o especial 
contributo teórico de Teun A. van Dijk, pensando-o à luz de uma renovação da Crítica do Direito.

\section{Estudos Críticos do Discurso: Elementos para uma Renovação da Crítica do Direito}

Os Estudos Críticos do Discurso (ECD), desenvolvidos pelo linguista holandês Teun A. van Dijk no âmbito da Análise Crítica do Discurso (ACD), parecem ser hoje um interessante ponto de interseção com a Crítica do Direito. Note-se que embora a ACD seja largamente adotada pela comunidade científica na atualidade, a proposta de van Dijk vai no sentido de mudar esta expressão para "Critical Discourse Studies" (CDS), ou seja, para Estudos Críticos do Discurso (ECD). E não se trata de uma mera mudança de etiqueta. Igualmente, a razão para tal mudança também não é apenas a de circunscrever seu próprio campo de estudos, mas sim a de destacar que os Estudos Críticos do Discurso não são um "método de análise do discurso" - como frequentemente se presume, sobretudo nas ciências sociais.

Para van Dijk não existe este tipo de método, de modo que os ECD podem utilizar qualquer método que seja relevante para os objetivos de suas pesquisas. Cabe observar que os métodos empregados são, em sua maioria, os mesmos utilizados nos estudos do discurso em geral. Diante destes argumentos, van Dijk (2012, pp. 10-11) adverte que, pela mesma razão, também a Análise do Discurso não poderia, pelo menos a rigor, ser considerada um "método". Nesse sentido, procuraremos demonstrar como os Estudos Críticos do Discurso de Teun van Dijk têm potencial para instrumentalizar análises dos fenômenos jurídico-sociais ao tempo em que permitem uma renovação da Crítica do Direito.

Os ECD podem ser definidos como um movimento científico interessado no desenvolvimento da teoria e da análise crítica da reprodução 
discursiva do abuso de poder e da desigualdade social (DIJK, 2012, p. 09). Van Dijk identifica, como domínio especial dos ECD, certos fenômenos sociais, problemas e temas específicos de pesquisa, relacionados geralmente com o papel do discurso, o uso linguístico e a comunicação social. Questões envolvendo o papel da mídia na contemporaneidade, a manipulação e a (des)informação social também aparecem situados como problemas de grande relevância para os ECD.

O instrumental epistemológico proposto por van Dijk mostra-se, assim, bastante útil no estudo das relações de dominação no âmbito social, auxiliando-nos a perceber o modo como se estruturam os discursos dominantes e a própria relação de dominação de certos grupos sobre outros. Percebe-se, dessa maneira, o valor dos ECD para pesquisas realizadas por linguistas, jornalistas, cientistas políticos, sociais, e, agora também, por juristas - pois, frise-se, não se detectou, pelo menos até ao presente momento, qualquer pesquisa jurídica crítica com recurso aos ECD de van Dijk.

Embora suas raízes se situem originalmente na linguística, os ECD possuem uma forte marca interdisciplinar, alcançando as ciências humanas e sociais e, conforme iremos propor, o próprio Direito. Por se tratar de um avançado projeto teórico, dirigido à problematização das propriedades semióticas do discurso ligadas às relações de poder na sociedade (DIJK, 2012, p. 09), os ECD podem possibilitar um olhar diferenciado sobre questões que já foram objeto de reflexões jurídicas em um passado não muito distante ${ }^{11}$.

Como sublinhado anteriormente, do ponto de vista epistemológico os ECD não podem ser definidos como um "método" de análise do discurso. Para van Dijk (2012, p. 11), o(s) método(s) a ser(em) utilizado(s) depende(m)

\footnotetext{
11 Referimo-nos, especificamente, a Luis Alberto Warat, que nos anos 1980 denunciara a necessidade de uma "análise crítica das linguagens jurídicas" com ênfase no "poder do discurso jurídico e com as funções político-ideológicas que este discurso cumpre nas condições materiais da vida social". Cfe. WARAT (1995, p. 09).
} 
muito do tipo de pesquisa que irá se realizar à luz dos ECD e, sobretudo, da natureza dos dados a serem estudados.

Entre os métodos "tradicionais" de Estudos do Discurso, utilizam-se, entre outros: a análise gramatical, a análise pragmática dos atos de fala e dos atos comunicativos e a análise de estruturas específicas: narrativa e argumentação - as quais bem podem ser utilizadas no estudo crítico, por exemplo, de decisões judiciais ${ }^{12}$.

Ainda sobre a questão metodológica, observe-se que, baseando-se nos ECD, não se analisa unicamente um objeto "verbal" autônomo, mas volta-se a atenção à interação situada, como um tipo de comunicação social, histórica, ou política, ou, em última análise, como uma prática social. Por isso, os ECD devem servir-se, especialmente, de métodos que se concentrem nas relações entre a estrutura social e a estrutura discursiva, demonstrando como a segunda pode ser influenciada pela primeira (DIJK, 2012, pp. 12-13).

Nesse sentido, os ECD permitem o estabelecimento de conexões reais entre conceitos, métodos de análise e interpretação de diferentes disciplinas, abrindo um diferenciado espaço interdisciplinar para a crítica jurídica. Entendemos, seguindo a linha proposta por van Dijk, que uma abordagem interdisciplinar do discurso jurídico não deve ser limitada à análise estrutural de seus vários níveis ou dimensões (sob pena de um retorno à semiótica ou à semiologia jurídicas), mas precisa, de igual modo, prestar atenção aos processos cognitivos e às chamadas representações de memória do discurso. Ou seja, segundo van Dijk (1985, p. 05), o armazenamento, a recuperação, as estratégias cognitivas, as limitações de memória e os procedimentos de organização eficazes para o processamento de informações são, também, muito relevantes no domínio dos ECD.

Além disso, uma característica originária da Análise Crítica do Discurso (apropriada pelos Estudos Críticos do Discurso) é o fato de que tais

\footnotetext{
${ }_{12}$ Sobre os métodos dos Estudos Críticos do Discurso, ver, sobretudo, DIJK (2012, p. 11 e seguintes).
} 
estudos podem ser livremente conduzidos e combinados com outras abordagens e subdisciplinas no âmbito das ciências humanas e sociais (DIJK, 2002, p. 96). Daí optarmos por trazer os ECD para o campo das ciências sociais aplicadas, especialmente para o Direito.

Existe, neste contexto epistemológico, uma grande quantidade de métodos, de diversas áreas, que podem ser utilizados e sistematicamente combinados, a depender do tipo de pesquisa realizada, como afirmamos anteriormente. Porém, como van Dijk destaca, apesar deste pluralismo metodológico, "há preferências e tendências em função do enfoque especial dos ECD sobre os aspetos de abuso de poder e, portanto, mais geralmente, sobre as condições e consequências sociais da escrita e da fala" (2012, p. 13).

É possível, neste contexto, que a expressão abuso de poder cause certo estranhamento. Todavia, não é incomum, nas relações sociais em geral, que haja abusos e usos ilegítimos do poder. Os ECD surgem, então, como um espaço crítico-reflexivo para estudarmos estes usos ilegítimos do poder, os quais podem se dar de diferentes formas: desde a (des)informação da mídia, até ao modo como os juristas dominam por meio de seu conhecimento técnico. Aliás, van Dijk prefere denominar tais formas de abuso de poder de dominação. Tal noção se refere à dimensão negativa de "abuso", remetendo, pois, às próprias consequências do uso (abusivo) do poder discursivo: a violação de direitos humanos ou civis das pessoas (DIJK, 2012, p. 28).

Há nos ECD, como facilmente e percebe, certo engajamento, uma espécie de "compromisso social" [e jurídico, poderíamos dizer, no âmbito deste estudo] por parte do pesquisador, o que significa dizer que este não é "neutro" em suas pesquisas, mas está comprometido, de algum modo, em favor dos grupos dominados na sociedade. E não se trata necessariamente de adotar uma postura polarizada ou mesmo polarizante ("Esquerda ou Direita"...), pois para van Dijk (2012, p. 13), não importa "se você é da Esquerda ou da Direita, a gramática da língua é a mesma para todos”. 
Em verdade - e van Dijk alerta bem sobre este ponto -, muitas pesquisas sociais consideradas "neutras" podem ter uma posição social, política, ou mesmo ideológica implícitas. Por outro lado, já se questionou no campo acadêmico se pesquisas comprometidas social e politicamente poderiam ser consideradas "científicas”. Sobre isso, van Dijk (2012, pp. 1516) afirmará que as acusações de um "viés" contra a pesquisa crítica são muito comuns, o que, por si só, já as faz merecedoras de uma análise crítica, pois o não comprometimento político é também uma escolha política.

Os ECD instituem, desta maneira, um espaço inter e multidisciplinar de crítica social, abrindo diferentes perspectivas de análise para os usos ilegítimos do poder, a dominação e a desigualdade social. E existe, neste espaço teórico, um profícuo diálogo com diferentes teorias sociais - como a Teoria Crítica da Escola de Frankfurt, para citar apenas um exemplo privilegiado.

Entre as preocupações de van Dijk no domínio dos ECD, encontramos, de modo bastante saliente, a problemática da manipulação social. Em suas análises, este autor nos mostra a íntima relação entre manipulação e poder. Conforme van Dijk (2006, p. 360), “(...) a manipulação como pretendida aqui é uma prática comunicativa e interacional, na qual um manipulador exerce controle sobre outras pessoas, geralmente contra sua vontade ou contra seus interesses". Trata-se, logo, de uma prática linguística que visa ocultar componentes ideológicos e, até certo ponto, ocultar a realidade, sendo, logo, um eficaz sustentáculo no estabelecimento de relações de poder.

Para Philippe Breton (1999, p. 20) a manipulação “apoia-se numa estratégia central, talvez única: a redução mais completa possível da liberdade de o público discutir ou de resistir ao que lhe é proposto". Trata-se, é certo, de uma forma antiga e bastante efetiva de se exercer a exploração e a dominação social. É o que entende, por exemplo, Vicente Romano (2008, p. 09), ao afirmar, em bela análise sobre a linguagem, que 
o uso manipulador da linguagem é tão antigo quanto a dominação de uns seres humanos sobre outros. Todos os dominantes, sejam feiticeiros, religiosos, políticos, económicos, intelectuais ou de quaisquer outras naturezas, utilizaram as palavras para confundir, aterrorizar, ocultar e manter a ignorância sobre as autênticas relações de dominação e exploração.

Note-se que neste rol dos dominantes apontado por Romano, podemos incluir, por exemplo, a mídia (que tão funesto papel exerce em relação ao Direito), visto que esta hoje se tornou responsável por propagar a desinformação, criando, muitas vezes, um cenário de enganação ou de manipulação ideológica na propagação de mensagens. Daí o alerta de Breton (1999, p. 20) ao afirmar que "a mensagem, em sua dimensão cognitiva ou sob sua forma afetiva, é concebida para enganar, induzir a erro, fazer crer no que não é".

Como sugerido, entre manipulação e poder existe uma indissociável e íntima relação. Para van Dijk, a manipulação se relaciona, especificamente, com usos ilegítimos do poder sendo, portanto, uma forma de dominação. A manipulação é uma forma de influência ilegítima, operada por meio do discurso, a partir da qual os manipuladores fazem os manipulados acreditar em (ou mesmo fazer) coisas que são de especial interesse do manipulador (e, geralmente, contra o interesse do manipulado).

Nesse sentido, a manipulação pode ser compreendida como um complexo fenômeno social, envolvendo interação e abuso de poder entre certos grupos e atores sociais. É complexo igualmente pelo facto de ser um fenômeno que se apresenta sob duas formas: primeiro, como um fenômeno cognitivo, pois sempre implica em manipulação das mentes dos participantes; segundo, como um fenômeno discursivo-semiótico, uma vez que a manipulação é exercida por meio de texto, conversa ou mensagens visuais (DIJK, 2006, pp. 360-361).

Acreditamos termos apresentado até o momento caracteres que desvelam certos entrelaçamentos designativos que amparam nossa tese de que os ECD de van Dijk possibilitam - desde que assumida uma postura 
inter/multidisciplinar rigorosa - uma atualização da Crítica do Direito, uma vez que existe uma espécie de equivalência funcional metalinguística entre os ECD e a Crítica do Direito. Em outras palavras, ambos buscam, cada qual em seu respectivo campo, realizar uma crítica social, fruto de certa inconformidade com o inscrito e o instituído na sociedade contemporânea sobretudo com as relações de dominação. Perseguindo objetivos distintos, mas com este importante fio condutor em comum, os ECD e o pensamento crítico do Direito podem ser aproximados na tentativa de se desamalgamar e compreender o discurso jurídico em suas (inter)relações com outros discursos (como o midiático ou o político, por exemplo), fazendo isso sob um viés marcadamente crítico e socialmente comprometido.

Entre os pontos que indicam a possibilidade de apresentação de uma nova proposta crítico-jurídica, encontra-se o elo entre discurso, sociedade e Direito. Dentre as dimensões do estudo do discurso, conforme propõe van Dijk, duas constituem o próprio "elo linguístico" entre Direito e sociedade: o estudo do uso da linguagem e o estudo da interação em situações sociais. Naturalmente, por discurso não podemos entender aqui o "mero uso da linguagem", uma vez que um dos papéis principais dos ECD é justamente o de descrever em que consiste o uso da linguagem, bem como quais são os seus componentes, como eles se ordenam e como, finalmente, eles acabam por ser utilizados em construções maiores. Tudo isso para defendermos que o discurso deve ser estudado não exclusivamente sob um viés linguísticogramatical, mas, de acordo com Teun van Dijk, como uma forma de interação social, relacionando-o, deste modo, ao próprio contexto social (1997, pp. 02-05).

Note-se que um estudo crítico do discurso jurídico pelas lentes dos ECD leva-nos, possivelmente, a um terreno ainda inexplorado pela teoria jurídica contemporânea. E, sem embargo, não se poderá afirmar que ao nos servirmos de certos métodos que os analistas do discurso comumente usam, cairemos no âmbito da análise linguística tradicional. Ora, como visto, os 


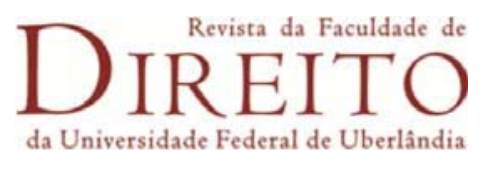

ECD possuem um domínio próprio de estudos que se aproxima das ciências sociais, embora, naturalmente, seu ponto de partida seja a própria linguística.

Ademais, os ECD permitem que percebamos que os discursos, como sugere van Dijk, não consistem em meras estruturas de sons ou gráficos, ou mesmo em formas abstratas de sentença (sintaxe). Ultrapassando o instrumental da linguística tradicional, os ECD se autodescrevem em termos de análise linguístico-social de ações sociais realizadas pelos usuários da linguagem em um nível micro (interpessoal) e macro (social), com forte apelo a uma reflexão acerca da sociedade e da cultura (DIJK, 1997, pp. 13-14).

Em face deste apelo sócio-cultural crítico, entendemos que os ECD de van Dijk podem trazer importantes aportes teóricos e práticos para o Direito. Enquanto nos estudos jurídicos semióticos e semiológicos tradicionais havia certo distanciamento (empírico, sobretudo, sublinhe-se) de relevantes problemáticas sociais (ideologia, poder, dominação, etc.) ${ }^{13}$, os estudos de van Dijk - tendo por principal objeto de análise a reprodução discursiva do abuso de poder e a consequente problemática da desigualdade social - sugerem como seu "complemento" as teorias e categorias provenientes das ciências sociais. Não há, portanto, qualquer sinal de incompatibilidade entre os ECD de van Dijk e certas teorias que informam o pensamento jurídico, muito pelo contrário: as análises realizadas acabarão por serem caracterizadas como descrições jurídicas qualitativas dos detalhes da estrutura discursiva.

\footnotetext{
${ }^{13}$ É importante observar que Warat (e também alguns de seus discípulos, como é o caso de Leonel Severo Rocha) ocupava-se, sim, com questões como ideologia, hegemonia e poder (Warat inclusive esboçaria, com grande sucesso, nos anos 1980, sua proposta epistemológica conhecida como "Semiologia do Poder"). Não obstante, a diferença fulcral entre estas perspectivas semióticas e semiológicas e a crítica jurídica que propomos à luz dos ECD, é que o discurso passará a ser objeto não apenas de meras análises teóricas, mas será estudado também do ponto de vista de suas estruturas e estratégias de fala e de escrita, servindo-se, portanto, de análises gramaticais, pragmáticas (atos de fala e atos comunicativos), retóricas, etc.
} 
Por outro lado, é importante sublinharmos que, ao estudarem-se as relações entre estruturas discursivas e estruturas sociais, não estamos diante de uma simples relação causal, ou mesmo de correlação. Há, por trás deste estudo, um complexo processo sociocognitivo, que envolve desde modelos mentais, até representações cognitivas dos atores sociais (por exemplo, as representações cognitivas dos atores do campo jurídico, como os juízes, por exemplo) (DIJK, 2012, pp. 14).

Por outro lado, entendemos que os ECD e a Crítica do Direito podem auxiliar na combinação tanto de aspectos teórico-metodológicos, quanto de aspectos empírico-sociais, para a estruturação de uma reflexão jurídica crítica mais condizente com as complexas configurações da sociedade contemporânea. Isto é, ao preocuparem-se com a problemática da ideologia e da dominação, os ECD fornecem um instrumental teórico que pode dotar a crítica jurídica de significativo alcance para a análise empírica de certas questões jurídico-sociais.

\section{Conclusão}

Este artigo visou apresentar, ainda que de modo bastante geral, os Estudos Críticos do Discurso de Teun A. van Dijk como referencial teóricolinguístico apto a permitir uma atualização da Crítica do Direito. O pensamento jurídico crítico pode surgir, pois, a partir deste referencial linguístico, como um privilegiado espaço para se detectar e delatar as sinuosidades e eventuais ardis do discurso jurídico.

Com efeito, um dos pontos de contato entre a Crítica do Direito e os ECD é a própria denúncia da função ideológica que subjaz à fundamentação de certas práticas sociais e jurídicas. Enquanto o pensamento crítico do Direito se dirige à análise das condições históricas do surgimento, produção e circulação do discurso jurídico, os ECD procuram dar uma atenção à análise dos elementos estruturais dos mais variados discursos sociais 


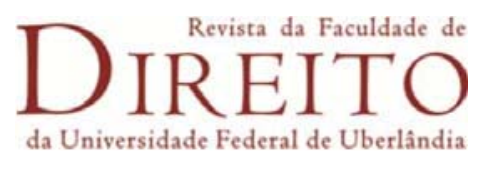

(midiático, político, jurídico, econômico, etc.), partindo de uma matriz interdisciplinar com forte apelo social. Assim, entendemos que o "encontro" destas duas perspectivas críticas pode auxiliar na imposição de limites ao exercício de poder no campo jurídico.

Por fim, entendemos que críticas jurídicas aos diferentes problemas que circundam as relações de poder na sociedade contemporânea devem se servir de um instrumental teórico-linguístico apto a desvelar o poder no âmbito discursivo. Nesse aspecto, os ECD de van Dijk permitem que se perceba, mais claramente, como o poder envolve, sobretudo, a capacidade de certos grupos subordinarem outros. O poder - visto sob esta óptica relaciona-se com os problemas da desigualdade e da dominação. E tais problemas devem ser objeto de uma reflexão jurídica atual comprometida com o social. Para tanto, um ponto de partida possível parece-nos ser a articulação dos ECD de van Dijk com a Crítica do Direito, visto que tal articulação pode orientar os lineamentos iniciais de uma "Crítica Linguística do Direito", mais atual e condizente com os caracteres da sociedade contemporânea.

\section{Referências}

ALEXY, Robert. Teoría de la Argumentación Jurídica. La Teoría del Discurso Racional como Teoría de la Fundamentación Jurídica. Trad. de Manuel Atienza e Isabel Espejo. Madrid: Centro de Estudios Políticos y Constitucionales, 2007.

ANSART, Pierre. Ideologias, Conflito e Poder. Trad. de Aurea Weissenberg. Rio de Janeiro: Zahar Editores, 1978.

BAKHTIN, Mikhail. Notas sobre Literatura, Cultura e Ciências Humanas. Organização, tradução, posfácio e notas de Paulo Bezerra. Notas da edição russa de Serguei Botcharov. São Paulo: Editora 34, 2017.

(Volochínov). Marxismo e Filosofia da Linguagem. Problemas Fundamentais do Método Sociológico na Ciência da Linguagem. Trad. de Michel Lahud e Yara Frateschi Vieira. 13 ${ }^{a}$ ed. São Paulo: Hucitec, 2009.

BITTAR, Eduardo C. B. Linguagem Jurídica. São Paulo: Saraiva, 2006.

BOURDIEU, Pierre. O Poder Simbólico. Trad. de Fernando Tomaz. 10 a ed. Rio de Janeiro: Bertrand Brasil, 2007.

BRETON, Philippe. A Manipulação da Palavra. Trad. de Maria Stela Gonçalves. São Paulo: Edições Loyola, 1999. 


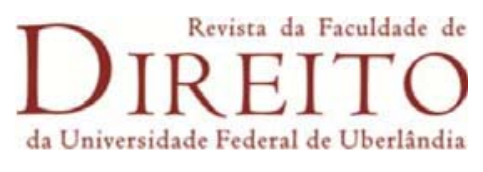

CÁRCOVA, Carlos María. Prólogo. In: MARÍ, Enrique E. et al., Materiales para una Teoría Crítica del Derecho. Buenos Aires: Abeledo-Perrot, 1991.

CARNAP, Rudolf. The Logical Structure of the World. Berkeley: University of California Press, 1969.

CONLEY, John M. and O’BARR, William M. Just Words, Law, Language and Power. Chicago: The University of Chicago Press, 1998.

DEMO, Pedro. Pesquisa e Construção do Conhecimento: Metodologia Científica no Caminho de Habermas. $7^{a}$ Edição. Rio de Janeiro: Tempo Brasileiro, 2012.

DIJK, Teun A. van. Discourse and Manipulation. In: Discourse \& Society, 17 (2), pp. 359-383, 2006.

Discurso e Poder. Org. Hoffnagel, Judith e Falcone, Karina. Trad. Hoffnagel, J. et al. $2^{\mathrm{a}}$ ed. $1^{\mathrm{a}}$ reimpressão. São Paulo: Contexto, 2012.

El Análisis del Discurso Social. In: GIALDINO, Irene V. de. La Construcción de Representaciones Sociales, Discurso Político y Prensa Escrita, Un análisis sociológico, jurídico y lingüístico. Barcelona: Editorial Gedisa, 1997.

Introduction: Levels and Dimensions of Discourse Analysis. In: DIJK, Teun A. van (Ed.). Handbook of Discourse Analysis (C3), 1985, Vol. 2.

Muldisciplinary CDA: a plea for diversity. In: WODAK, Ruth and MEYER, Michael. Methods of Critical Discourse Analysis. London: SAGE Publications, 2002. pp. 249-283.

Principles of Critical Discourse Analysis. In: Discourse \& Society, 4 (2), 1993,

Semântica do Discurso e Ideologia. In: PEDRO, Emília R. (Ed.). Análise Crítica do Discurso. Lisboa: Editorial Caminho, 1997.

The Study of Discourse. In: DIJK, Teun A. van (Ed.). Discourse as Structure and Process. Discourse Studies 1. A Multidisciplinary Introduction. London: SAGE Publications, 1997.

The Study of Discourse. In: DIJK, Teun A. van (Ed.). Discourse as Structure and Process. Discourse Studies 1. A Multidisciplinary Introduction. London: SAGE Publications, 1997.

FERRAZ JR., Tércio Sampaio. Direito, Retórica e Comunicação: subsídios para uma pragmática do discurso jurídico. São Paulo: Saraiva, 1973.

Teoria da Norma Jurídica. $4^{\mathrm{a}}$ ed. Rio de Janeiro: Forense, 2005.

FRAGALE FILHO, Roberto e REZENDE ALVIM, Joaquim L. de. O Movimento 'Critique du Droit' e seu Impacto no Brasil. In: Revista Direito GV, 6, Vol. 3, N. 2, pp. 139-164, Jul./Dez. 2007.2 Disponível em: $<$ http://bibliotecadigital.fgv.br/ojs/index.php/revdireitogv/article/view/35186>. Acesso em: 23 de novembro de 2014.

HESPANHA, António Manuel. Panorama Histórico da Cultura Jurídica Europeia. Sintra (Portugal): Publicações Europa-América, 1997.

KELSEN, Hans. Teoria Pura do Direito. Trad. de João Baptista Machado. $6^{a}$ ed. São Paulo: Martins Fontes, 2000.

LUHMANN, Niklas. Sistema Jurídico y Dogmática Jurídica. Trad. de Ignacio de Otto Pardo. Colección 'Estudios Constitucionales'. Madrid: Centro de Estudios Constitucionales, 1983. 


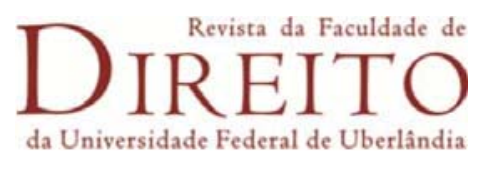

LYRA FILHO, Roberto. Para um Direito sem Dogmas. Porto Alegre: Sérgio Antônio Fabris Editor, 1980.

MIAILLE, Michel. Uma Introdução Crítica ao Direito. Trad. de Ana Prata. Lisboa: Moraes Editores, 1979.

PAŠUKANIS, Evgeny. A Teoria Geral do Direito e o Marxismo. Trad. de Soveral Martins. Coimbra: Centelha (Col. Perspetiva Jurídica), 1977.

PEDRO, Emília Ribeiro. Análise Crítica do Discurso: aspetos teóricos, metodológicos e analíticos. In: PEDRO, Emília R. (Ed.). Análise Crítica do Discurso. Lisboa: Editorial Caminho, 1997.

PEIRCE, Charles Sanders. Semiótica. $3^{\text {a }}$ ed. São Paulo: Perspectiva, 2003.

RESENDE, Viviane de Melo e RAMALHO, Viviane. Análise de Discurso Crítica. São Paulo: Contexto, 2016.

ROCHA, Leonel Severo. Semiologia, Semiótica e Teoria do Direito. In: ROCHA, L. S. Epistemologia Jurídica e Democracia. $2^{a}$ ed. São Leopoldo: Unisinos, 2005.

ROMANO, Vicente. A Intoxicação Linguística: o uso perverso da língua. Trad. de Rui Pereira. Porto: Deriva, 2008.

SAUSSURE, Ferdinand de. Curso de Linguística Geral. Organizado por Charles Bally, Albert Sechehaye, com colaboração de Albert Riedlinger. Trad. de Antônio Chelini e José Paulo Paes. 34 ed. São Paulo: Cultrix, 2012.

SILVA, Joana Aguiar e. Para uma Teoria Hermenêutica da Justiça: Repercussões Jusliterárias no Eixo Problemático das Fontes e da Interpretação Jurídica. Coimbra: Almedina, 2011.

VIEHWEG, Theodor. Topica y Jurisprudencia. 1. ed. Madrid: Taurus, 1986.

WARAT, Luís A. O Direito e sua Linguagem (com a colaboração de Leonel Severo Rocha). $2^{\mathrm{a}}$ ed. Porto Alegre: Sérgio Antônio Fabris, 1995.

À Procura de uma Semiologia do Poder. In: Sequência - Estudos Jurídicos e Políticos, Volume 02, no 3 (1981), pp. 79-83, UFSC - Florianópolis, SC, Brasil. Disponível em: <https://periodicos.ufsc.br/index.php/sequencia/article/view/17232>. Acesso em: 21 de julho de 2018.

As Vozes Incógnitas das Verdades Jurídicas. In: Sequência - Estudos Jurídicos e Políticos, Volume 08, no 14 (1987), pp. 58-59, UFSC - Florianópolis, SC, Brasil. Disponível em: <https://periodicos.ufsc.br/index.php/sequencia/article/view/16456>. Acesso em: 16 de novembro de 2017.

; ROCHA, Leonel Severo e CITTADINO, Gisele. O Poder do Discurso Docente das Escolas de Direito. In: Sequência. $2^{\circ}$ semestre de 1980.

WODAK, Ruth. What CDA is about - a summary of its history, important concepts and its developments. In: WODAK, Ruth and MEYER, Michael. Methods of Critical Discourse Analysis. London: SAGE Publications, 2002.

YAGUELLO, M. Apresentação. In: BAKHTIN, Mikhail (Volochínov). Marxismo e Filosofia da Linguagem. Problemas Fundamentais do Método Sociológico na Ciência da Linguagem. Trad. de Michel Lahud e Yara Frateschi Vieira. 13 ${ }^{\mathrm{a}}$ ed. São Paulo: Hucitec, 2009.

Artigo recebido em: 13/01/2020.

Aceito para publicação em: 30/04/2020. 